\title{
A Rate-based Approach to Cleaning-In-Place
}

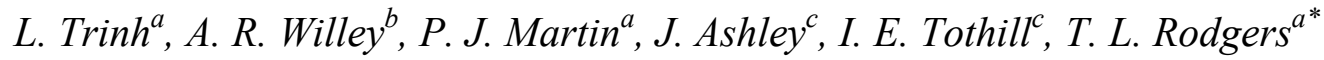 \\ ${ }^{a}$ School of Chemical Engineering and Analytical Sciences, University of Manchester, \\ Manchester, M13 9PL, UK \\ ${ }^{\mathrm{b}}$ Safety and Environmental Assurance Centre, Unilever R\&D, Colworth Science Park, \\ Sharnbrook, Bedford, MK441LQ, UK \\ ${ }^{\mathrm{c}}$ Cranfield University, Advanced Diagnostics and Sensors Group, Bedford, MK43 0AL, UK \\ *Tom.Rodgers@manchester.ac.uk
}

\section{Abstract}

Fouling is a major problem in the food industry. In cases where allergens are involved, excessive cleaning of food processing equipment often takes place to ensure allergen levels are reduced to acceptable levels. Experimental trials were conducted in a pilot scale cleaning rig to assess the effect of fluid flow rate and temperature on the removal rate of milk paste during cleaning-in-place. Conductivity measurements taken during trials were analyzed to produce an equation enabling calculation of the cleaning rate with water temperature, flow rate, initial deposit mass, and time. The rate of cleaning with detergent was also investigated. This methodology produces a rate based expression for cleaning, which can be applied to other products, and can be used to determine the time when cleaning is complete, the extent of a cleaning process, or when the pre-rinse should be replaced with a detergent rinse. This 
prevents over-cleaning and therefore reduces the costs associated with over-cleaning through energy, material and loss of production time.

\section{Keywords}

Transport Phenomena and Fluid Mechanics, Cleaning-In-Place (CIP), Cleaning Rate, Fouling

\section{Introduction}

Fouling occurs rapidly during food processing as deposits adhere to equipment surfaces ${ }^{1}$. This fouling reduces equipment efficiency and functionality, can cause microbial growth within equipment, and carry over to new batches can be life threatening for individuals with food allergies.

Adhesion to a surface is dependent on surface energy and surface roughness. Attempts to reduce fouling without altering process conditions include the use of surface modification ${ }^{2,3}$. However, whilst reductions in fouling may be made, extensive research into fouling has not yet found a way to eliminate $i t^{4}$. Fouling is often unavoidable due to it being caused by necessary thermal processing conditions, which ensure product safety ${ }^{5}$. This increases the importance of the cleaning process. Industrial cleaning often occurs by Cleaning-In-Place (CIP) therefore increasing efficiency by eliminating the time consuming step of dismantling equipment. This can either be a partly or fully automated in-situ process, where the cleaning fluid is circulated through the rig. There are typically several stages in the CIP process. The key stages are:

- Pre-rinse. Use of water to remove bulk of the product

- Detergent rinse. Use of detergent to remove remaining product 
- Post-detergent rinse. Use of water to remove detergent

The temperatures these stages occur at are product/detergent dependent, and the cleaning fluid may be recirculated or sent directly to drain. However, typical pre-rinse conditions consist of water at a velocity of about $1.5 \mathrm{~ms}^{-1}$ and temperature of around $60^{\circ} \mathrm{C}$. Typically, water is sent to drain during the pre-rinse stage and recycled during the detergent rinse stage to optimize use of the detergent ${ }^{6}$.

When removing a deposit, adhesive forces between the deposit and the equipment surface, and cohesive forces in the deposit, must be overcome. Some deposits will be predominantly adhesive and others predominantly cohesive, which can affect how they should be cleaned. A micromanipulation technique, which consists of drawing a stainless steel $\mathrm{T}$ shaped probe across the surface of the deposit whilst measuring the force to do this can be used to determine the nature of the deposit. For example, milk deposits are adhesive ${ }^{7}$ and are generally removed using both acidic and alkaline detergents to remove the organic and inorganic components of the deposit. This involves three stages ${ }^{8}$ : Initially the cleaning fluid penetrates into the solid deposit causing it to swell and increasing the voidage of the deposit, and then is removed uniformly by the fluid. The remaining deposits are eroded away in patches and are more sensitive to flow rate than the uniformly removed patches.

As a result of the problems resulting from fouling, CIP is conducted routinely. It is an expensive process, costing materials, energy, production time and therefore income. As a result, the higher the target level of cleanliness, the more costly the process. Optimizing cleaning would improve environmental sustainability, and ensure sufficient rather than excessive cleaning and therefore benefit companies. A key step for optimizing cleaning is in measuring the process. CIP can be monitored either on-line or off-line, with on-line giving real time data and therefore preferred for process efficiency. 
CIP is a water intensive process. Reducing the quantity of water used results in large cost savings. Fan et $\mathrm{al}^{9}$ looked into reusing water during the pre-rinse stage by recirculating it around the rig and found no significant difference in the effectiveness between used and unused water, due to mechanical forces being a key factor at this stage. Recirculation of used water is also only feasible after bulk recovery of the product and therefore is dependent on product type.

Jude and Lemaire ${ }^{10}$ listed some methods and the possible downsides of them that food and beverage manufacturers have adopted to increase the efficiency of their CIP processes. These include using a different chemical detergent or detergent concentration, altering cleaning times and water temperature, using different processing lines, using enzymes, using ecofriendly chemicals, using ozonated water, and operating more sustainably by switching off equipment when not in use and replacing faulty parts.

Pressure drop is frequently used to monitor equipment cleanliness. Whilst useful for monitoring the cleaning of large quantities of deposit, the method is not of sufficient sensitivity for monitoring small quantities of deposit, which would still contain allergens. Martin et $\mathrm{al}^{11}$ highlighted the need for an improved approach to verify equipment cleanliness. They utilized the concentration of outlet cleaning fluid to infer the cleanliness of the rig, with concentrations of zero implying the rig is clean. However, this approach does not take into account deposits that remain in the rig. Christian and Fryer ${ }^{12}$ used heat transfer coefficient and pressure drop to assess when the rig was $90 \%$ clean and found heat transfer more effective in monitoring the removal of the last quantities of deposit. Van Asselt et $\mathrm{al}^{13}$ illustrated that conductivity can be used to monitor cleaning and distinguish between the different cleaning phases. Asteriadou et $\mathrm{al}^{4}$ used visual observations, heat transfer coefficient and image analysis to monitor cleanliness. Khalid et al ${ }^{14}$ also analyzed images taken from a 
video of the cleaning process, assessing the change in area the deposit covered. This method is especially effective if the image analysis also takes into account the thickness of the deposit. Palabiyik et $\mathrm{al}^{6}$ utilized turbidity meters to verify cleanliness. However, the use of turbidity's effectiveness depends upon the deposit being cleaned, i.e. the deposit must change the opaqueness of the cleaning fluid. Fuchs et $\mathrm{al}^{15}$ measured deposit thickness using UV lamps to illuminate tracers, which were detected by an optical device. Ideally the equipment used to monitor cleanliness should be sensitive (a measurable change in the measured property around the end of the cleaning process), non-destructive and non-invasive, such as ultrasound. This method was assessed by Úbeda et $\mathrm{al}^{16}$ for plate heat exchangers in the milk industry. Liu et al ${ }^{17}$ developed a technique to monitor the adhesive and cohesive strength of milk deposits under different cleaning conditions, which can be used to optimize the cleaning protocol.

Factors affecting cleaning include: mechanical action, i.e. fluid velocity; chemical action, i.e. detergent concentration; temperature; and time. To optimize cleaning efficiency, these parameters should be at their optimal for the deposit. Literature in this field generally shows an increase in detergent concentration, cleaning fluid temperature, and cleaning fluid velocity increases the cleaning rate, up to an optimal for each parameter, which tend to be similar for temperature and velocity. Minimal values also exist for the parameters, below which cleaning is ineffective $e^{9,12,13,17}$. However, changing these parameters to reduce the cleaning time can incur costs, which must be balanced against the time saved. Piepiórka-Stepul et al ${ }^{18}$ assessed the cost in energy of heating up the cleaning fluid and pumping it at the desired velocity against the time taken to remove the deposit, to ensure cleaning was sufficient and energy usage minimal. 
Food intolerances and allergies affect a significant proportion of the population (In 2010 it was estimated that $44 \%$ of British adults now suffer from at least one allergy ${ }^{19}$ ). The Food Standards Agency has identified milk protein as a major allergen ${ }^{20}$. Milk is a common ingredient of many food products and used widely in the food industry, in powdered and fluid form. Dairy fluids cause a severe fouling problem in thermal processing equipment ${ }^{17}$ and the type of deposit formed depends on the temperature the milk proteins are exposed to ${ }^{12 .}$ Food companies incorporate rigorous cleaning regimes to ensure allergen levels are within an acceptable range and prevent cross-contamination of allergens from one product to another, which can result in product recall and brand damage. This is necessary as it is difficult to validate that equipment is clean ${ }^{10,21}$ and the brand damage resulting from product recall due to safety discourages experimentation with the cleaning parameters. Cleaning is currently checked through periodic off-line analysis of process swabs ${ }^{11 .}$

Gillham et $\mathrm{al}^{8}$ utilized pulsed cleaning to reduce the overall removal time of milk deposits in food processing equipment. The reduction in removal time was either caused by the increase in wall shear stress or enhanced mass transfer of the cleaning fluid to the deposit. The low frequency pulses did not have any affect during the swelling phase but was found to reduce the removal time of the deposits in the latter two phases.

This work assesses both the pre-rinse and detergent-rinse stages of cleaning using recycled water/detergent and therefore the variables investigated were the temperature, velocity of the water, and the cleaning time. Using the results a method that produces a calculation is presented, which can be used to optimize the pre-rinse cleaning phase by identifying when mechanical action of the water is no longer effective and therefore the optimum time for switching to the detergent phase. As well as improving the efficiency of the CIP process, this 
saves resources and therefore money for those adopting the method through minimizing the number of trials conducted to calculate the optimum time to switch to the detergent phase.

\section{Methods and Materials}

A pilot scale cleaning rig consisting of a series of pipes of $36 \mathrm{~mm}$ in internal diameter and a removable test section was used to investigate the removal of a deposit of milk paste using water from the surface of the test section. The cleaning rig is made from stainless steel and the removable test section is made of polycarbonate with Perspex viewing windows. The polycarbonate test section has internal dimensions of $12 \mathrm{~mm}$ x $40 \mathrm{~mm} \times 700 \mathrm{~mm}$ and a stainless steel sheet along its length, on which the deposit is placed. The deposit can be observed both front on and from above through the Perspex window during cleaning. The rig is fully heat lagged reducing heat loss.

The rig consists of a 40 liter vessel containing a heater, temperature probe, and thermostat and can be operated up to $80^{\circ} \mathrm{C}$. The vessel can be filled with fluid, which feeds two centrifugal pumps that provide fluid to the test section up to a velocity of $1.5 \mathrm{~ms}^{-1}$. A by-pass around the test section enables the rig and the vessel contents to be heated, whilst the test section is prepared until the desired processing conditions are reached. Instrumentation within the rig includes a magnetic flow meter, pressure sensors, conductivity sensors and temperature sensors, which are connected to a data logger that records this information every five seconds. The instrumentation is listed in Table 1. Collected data can be exported from the device for viewing and analysis. Figure 1 shows the cleaning rig, illustrating the positioning of instrumentation within the rig.

Granulated skimmed milk (Milfresh Gold, Aimia Foods, Haydock, Merseyside, United Kingdom) and tap water (Clarke hardness 2.3 , conductivity $120 \mu \mathrm{S} \mathrm{cm}{ }^{-1}$ ) were mixed together to form a paste (10 g milk power per $3 \mathrm{~g}$ water), which was rolled to a chosen height 
onto the test section. The height, $h$, as illustrated in Figure 2, was controlled by rolling the milk paste between metal bars clamped onto either side of the test section as illustrated in Figure 3 (standard of $6 \mathrm{~cm}$ long, and $3 \mathrm{~mm}$ thick, variations from this are noted in the results). This was then left for 1 hour to dry before being added to the cleaning rig. The quantity of milk paste on the test section was intentionally varied if needed, monitored by mass (but the same mass rolled to the same volume). The test section was inserted and secured into the cleaning rig using screws, and the cleaning fluid circulated around the rig at $40-80^{\circ} \mathrm{C}$ and $1.0-$ $1.5 \mathrm{~ms}^{-1}$. Rather than sending the cleaning fluid immediately to drain, the cleaning fluid was recycled around the rig. Each of the experimental conditions were repeated between 4 and 6 times to check the repeatability of the cleaning process; Figure 4 shows an example of this repeatability. In this figure there are some spikes in removed mass, e.g. Run 3 at about 1250 seconds, these are not real and are due to the conductivity meter reading a higher value of conductivity, this is most likely due to some material stuck to the conductivity meter for a short time. The experiment was undertaken for 1 hour in this case.

The cleaning fluid either consisted of water or the detergent, MIP SCA (Ecolab, Northwich, United Kingdom. Alkali cleaner containing Sodium Hydroxide), which was used at a 2\% concentration (conductivity of $110 \mathrm{mS} \mathrm{cm}^{-1}$ ).

Using conductivity measurements, the time required to remove the deposit from the test section was assessed. The change in conductivity was around $20 \%$ of the water conductivity (ranged from $120 \mu \mathrm{S} \mathrm{cm}^{-1}$ to $140 \mu \mathrm{S} \mathrm{cm}^{-1}$ ), for the water tests we used the Condumax CLS15 conductivity meter, which had a range of $0-200 \mu \mathrm{S} \mathrm{cm}^{-1}$. The change in conductivity was around $2 \%$ of the detergent conductivity $\left(110 \mathrm{mS} \mathrm{cm}^{-1}\right)$, for these tests we used a Smartec CLD 18, which can record conductivities up to $1000 \mathrm{mS} \mathrm{cm}^{-1}$, we however set the meter up using references of 100 and $150 \mathrm{mS} \mathrm{cm}^{-1}$. 
A calibration curve was created using conductivity measurements in the presence of a known quantity of milk granules; Operating over the range of temperatures and maximum velocity to ensure thorough mixing, the milk granules were added to the filled vessel. The change in conductivity measurements was taken for each quantity of milk granules and a line fitted through these nine data sets. As the conductivity changes with temperature, a calibration was also conducted to take into account these changes (using the standard calibration on the conductivity meter).

Figure 5 shows the conductivity change from the conductivity of water at varying milk concentrations ranging from $0-0.25 \mathrm{~g} \mathrm{l}^{-1}$. It shows an increase in the change in conductivity as the concentration of milk granules increase. The more conductive milk granules dissolve in the hot water resulting in an increase in the overall conductivity of the fluid measured by the conductivity meters. When adjusted for temperature there were no appraisable differences between the different temperatures. The change in conductivity, $\sigma\left(\mu \mathrm{S} \mathrm{cm}{ }^{-1}\right)$, with the concentration, $C\left(\mathrm{~g} \mathrm{l}^{-1}\right)$, can be given by,

$$
\sigma=72.5 C
$$

Using equation (1), derived from Figure 5, and knowledge of the total water volume the mass of milk removed from the deposited paste at a given time was calculated.

\section{Results and Discussion}

Observation of paste removal with water was found in agreement with Fryer and Asteriadou ${ }^{21}$ to depend upon the rate of two events:

- The removal of loosely adhered paste 
- The diffusion of water into the paste to produce a removable paste

The results of the trials are presented below to assess the individual effect of different cleaning parameters on the cleaning time.

\subsection{Effect of Temperature}

As the temperature increases the time taken to clean the milk paste decreases; the rate of cleaning therefore increases. Figure 6 shows an example of the effect of changing the temperature on the cleaning rate at a velocity of $1.5 \mathrm{~ms}^{-1}$. The different cleaning phases are observed from the figure, the removal rate of the paste is highest initially and decreases with cleaning time, before leveling off due to there being less paste present and also because at this stage in cleaning the water is ineffective at removing the paste. This removal pattern is more prominent at the higher flow rates and higher temperatures. For example it is much clearer in the $80^{\circ} \mathrm{C}$ clean then the $40^{\circ} \mathrm{C}$ clean.

Figure 6 also shows that the removal of milk paste at $40^{\circ} \mathrm{C}$ is significantly less effective in comparison to the trials conducted at the highest temperatures. This is similar to Asteriadou et $\mathrm{al}^{4}$ who investigated the removal of protein deposits from sweet condensed milk from pipework and found that as the temperature increased from $20^{\circ} \mathrm{C}$ to $80^{\circ} \mathrm{C}$, the removal time of the deposit was less. Their results also showed that as the temperature increased, the difference in cleaning time between one temperature and another decreased.

Goode et $\mathrm{al}^{22}$ investigated the removal of yeast deposits with water at $30^{\circ} \mathrm{C}, 50^{\circ} \mathrm{C}$ and $70^{\circ} \mathrm{C}$, and found that less deposit cold be removed at $70^{\circ} \mathrm{C}$. They suggested the high temperature changed the rheology of the deposit, making it more elastic and therefore more difficult to remove. Cole et $\mathrm{al}^{23}$ observed a decrease in cleaning time of toothpaste from $20-40^{\circ} \mathrm{C}$, but limited benefit in further temperature increases. Fan et $\mathrm{al}^{9}$ assessed the removal of a protein 
deposit from pipework at temperatures of $22^{\circ} \mathrm{C}, 45^{\circ} \mathrm{C}$ and $67^{\circ} \mathrm{C}$, and saw the quantity of deposit remaining decreased after a $20 \mathrm{~s}$ contact time as the temperature increased.

\subsection{Effect of Velocity}

With increasing velocity the time taken to clean the milk paste decreases; therefore, the rate of cleaning increases. Figure 7 shows an example of the effect of changing the velocity on the cleaning rate at a temperature of $40^{\circ} \mathrm{C}$. It is expected that higher velocities are more effective for cleaning due to the increasing wall shear stress. The effect of increasing the velocity on the rate of cleaning is less than that of increasing the temperature, compare Figure 6 to Figure 7, and later to the values of the exponents in equation (3). However, at higher temperatures the effect of increasing the velocity is greater. This is similar to Asteriadou et $\mathrm{al}^{4}$ who investigated the removal of protein deposits from sweet condensed milk from pipework at flow rates ranging from 4-16 $1 \mathrm{~min}^{-1}$ (approx. $0.15-0.6 \mathrm{~m} \mathrm{~s}^{-1}$ ), and found a decrease in cleaning time as the flow rates increased, with a greater difference between the flow rates at higher temperatures such as $80^{\circ} \mathrm{C}$, compared to $20^{\circ} \mathrm{C}$.

Goode et $\mathrm{al}^{22}$ investigated the removal of yeast deposits with water at $0.26 \mathrm{~ms}^{-1}, 0.4 \mathrm{~ms}^{-1}$ and $0.5 \mathrm{~ms}^{-1}$ at 4 different temperatures ranging from $20-70^{\circ} \mathrm{C}$. The authors only found a significant difference in cleaning rates at $70^{\circ} \mathrm{C}$. The results from Cole et al ${ }^{23}$ saw a decrease in removal time for toothpaste as the velocity of the cleaning fluid increased from $1-3 \mathrm{~ms}^{-1}$ at $40^{\circ} \mathrm{C}$. Fan et $\mathrm{al}^{9}$ assessed the removal of a protein deposit from pipework at velocities of 0.72 $\mathrm{ms}^{-1}, 1.25 \mathrm{~ms}^{-1}$ and $2.26 \mathrm{~ms}^{-1}$, and observed a decrease in the quantity of the deposit remaining after a $20 \mathrm{~s}$ contact time as the velocity of the water increased.

\subsection{Effect of Quantity of Paste on Cleaning}

In industrial processes, due to pipe work being of different lengths the amount of deposited material can be different, even though the amount per unit length of pipe will be the same. We also wanted to check the independence of our measured cleaning rates to the size of the 
sample. Figure 8 shows the removal of two different volumes of paste at $60^{\circ} \mathrm{C}$ and $1.5 \mathrm{~ms}^{-1}$. These pastes were rolled out to the same height and depth so differences in the volume were in the length, $l$, across the test section. The removal rate per unit area are the same regardless of the size of the sample, and the cleaning conditions. This means that the cleaning rate can be applied to straight pipe work different lengths.

Cole et $\mathrm{al}^{23}$ filled pipes of the same internal diameter and a length of $0.3 \mathrm{~m}, 1 \mathrm{~m}$ and $2 \mathrm{~m}$ with toothpaste to assess the effect of scale on removal. The authors did not find a trend in the cleaning time corresponding to pipe length, but the cleaning times were very similar.

\subsection{Calculation of Cleaning Rate}

Examining the variation of the removed mass per unit area, $M\left(\mathrm{~g} \mathrm{~m}^{-2}\right)$, with time reveals that the rate of cleaning can be given by an expression of the form,

$$
\frac{d M}{d t}=A t^{-n}
$$

where $A$ is a pre-exponential factor equal to the initial cleaning rate, and $n$ is the power that represents the rate of decrease of the cleaning rate.
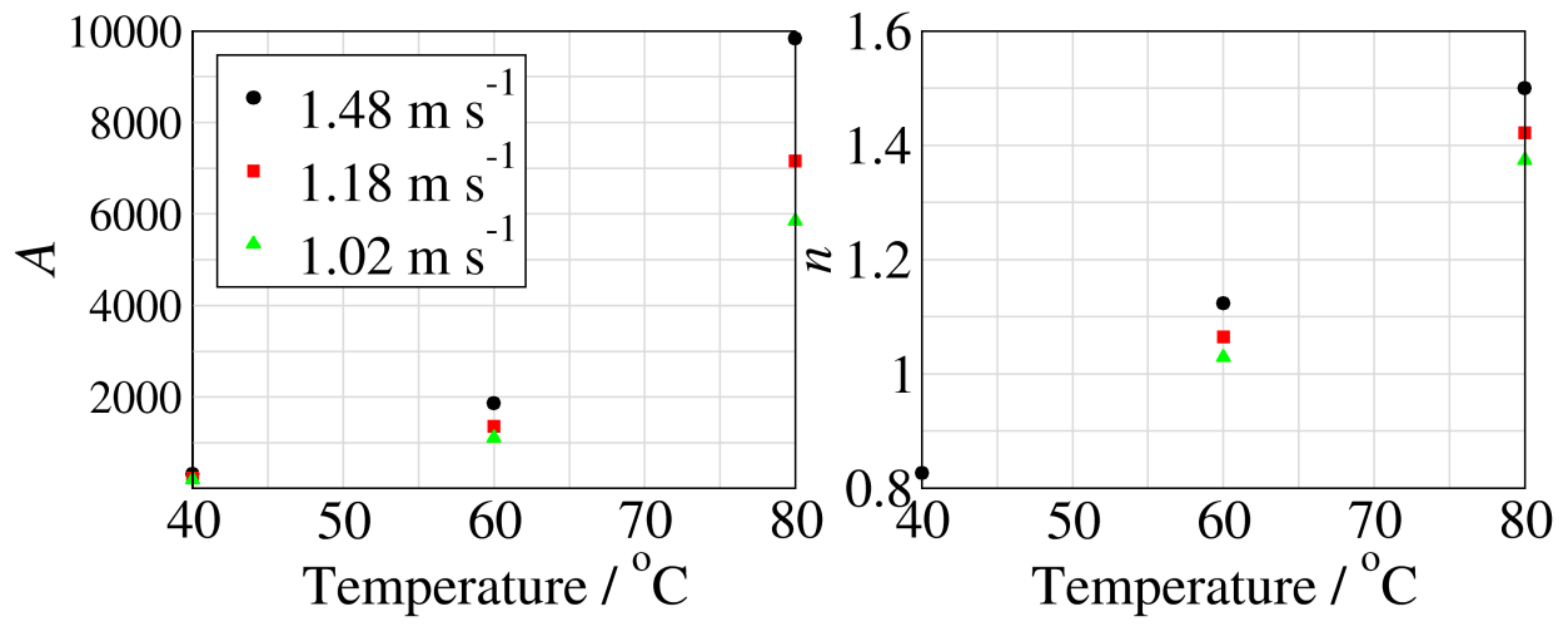

Figure 9 shows the variation of these parameters with the temperature and velocity, fitted for all the data collected in the paper. This emphasizes the fact that the cleaning rate increases 
more with increasing velocity at higher temperatures, i.e. the value of $A$ changes more with velocity at higher temperatures. The value of $n$ increases with increasing temperature, meaning that at higher temperatures the rate of cleaning reduces faster, this is most likely due to the fact that the paste is removed more, so less remains at longer times. The value of $n$ also increases with velocity, increasing more at higher temperatures, in fact at $40{ }^{\circ} \mathrm{C}$ the values are essentially identical.

The values of $A$ and $n$ can be fitted to a power law expression in terms of the temperature, $T$ (K), and the flow Reynolds number, Re, as below,

$$
\begin{aligned}
& A=1.58\left(\frac{T}{273}\right)^{28.5}\left(\frac{\mathrm{Re}}{10000}\right)^{1.40} \\
& n=0.331\left(\frac{T}{273}\right)^{4.96}\left(\frac{\mathrm{Re}}{10000}\right)^{0.236}
\end{aligned}
$$

This is the fit to the parameters in Figure 9. In this case the Reynolds is calculated using the hydraulic radius of the section cleaned. For the system used this is $0.0185 \mathrm{~m}$.

The average error for this expression is $5.53 \%$. Figure 10 gives an example of how this equation fits the mass removed plot for $1.48 \mathrm{~ms}^{-1}$ at the range of temperatures from 40 to $80^{\circ} \mathrm{C}$. As the exponent on the temperature is higher than that on the Reynolds number, the effect of changing the temperature has more of an effect on the cleaning rate compared to changing the velocity.

\subsection{Effect of Thickness of Paste on Cleaning}

The above results are based on pastes of the same thickness $(3 \mathrm{~mm})$, which is typical of industrial milk fouling thicknesses. However, the effect of the paste thickness on the rate of 
cleaning should be explored. Two pastes of the same mass were rolled out on the test section to different heights. Figure 11 shows the quantity of milk paste removed with time for the two pastes. The removal rate for the $1 \mathrm{~mm}$ tall paste was lower than the $3 \mathrm{~mm}$ paste throughout the cleaning process. This effect was seen under various conditions tested.

For the generated expression for the cleaning rate to fit the removed mass data for the $1 \mathrm{~mm}$ sample only the value of $A$ needs to be modified; the value of $n$ stays the same. The value of $A$ can be modified to take the fouling initial height, $h(\mathrm{~mm})$, into account, such that,

$$
A=0.527 h\left(\frac{T}{273}\right)^{28.5}\left(\frac{\mathrm{Re}}{10000}\right)^{1.40}
$$

As the variation with temperature and flowrate was the same with the different thicknesses. Figure 11 shows the above expression plotted with the measured data as the straight lines. It can be seen that this fits the data well. Due to this the initial amount of paste can be taken into account when trying to optimize the operation and cleaning of a process.

\subsection{Effect of Detergent}

As previously stated after the initial water pre-rinse a detergent wash is used. This allows removal of materials that cannot easily be removed with the water, or potentially need a chemical reaction to aid removal. The experiments were repeated, with the cleaning fluid changed to the detergent, MIP SCA, to investigate how this affected the cleaning rate. Figure 12 shows the quantity of milk paste removed with time for detergent compared to water. The removal of the paste is much faster using the detergent. For the velocity of $1.48 \mathrm{~ms}^{-1}$ the cleaning rate with detergent has been investigated under a range of temperatures to allow calculation of the parameters $A$ and $n$. Figure 13 shows the variation of these parameters with the temperature. The values of $A$ are much larger than with water emphasizing that the initial 
cleaning rate is faster. The values of $n$ are also much lower than with water, this means that the cleaning rate reduces at a slower rate. Cleaning with the detergent is much more efficient than with water; however, practically cleaning with detergent is restricted due to cost of the detergent and its disposal.

\section{Conclusions}

Fouling deposits vary in their complexity; different deposits have different ideal methods of cleaning. Materials like milk fouls by leaving hard deposits when thermally precipitated (or heat treated) on the pipe walls, or softer deposits without heat treating, while the center of the pipe is easily cleaned (or flushed) as it is free flowing. The results presented here for cleaning trials on milk paste demonstrated the effect of different cleaning parameters on the removal of the milk paste. By combining these results to assess the effect of different cleaning variables; temperature, velocity, paste thickness, and detergent use; an equation was formed, which allows calculation of the cleaning rate with time,

$$
\begin{gathered}
\frac{d M}{d t}=A t^{-n} \\
A=0.527 h\left(\frac{T}{273}\right)^{28.5}\left(\frac{\mathrm{Re}}{10000}\right)^{1.40} \\
n=0.331\left(\frac{T}{273}\right)^{4.96}\left(\frac{\operatorname{Re}}{10000}\right)^{0.236}
\end{gathered}
$$

With knowledge of the costs of the cleaning materials and the process, equations (6) - (8) can be used to optimize cleaning cycles and allow prediction of the optimum time to change to a detergent wash. Although equations (6) - (8) are only fully applicable to cleaning of milk 
paste, this paper provides a good framework to allow these types of equations to be developed for other materials. This is then useful for companies to reduce their energy usage, as currently they tend to over clean their equipment, using considerably more energy than necessary. Due to variations in deposits and processing equipment, it should be used as a guide to determine the optimum time under the chosen conditions. This saves the companies money and time in attempting to optimize parameters.

\section{Acknowledgements}

The authors gratefully acknowledge the financial support from Innovate UK and Food Standards Agency under the TSB Nutrition for Life - Providing Safe and Healthy Foods, 101733: "A novel integrated process monitoring approach to enhance food safety through online analysis of allergens" grant. They also acknowledge the help of The University of Manchester's CEAS workshop for equipment modification.

\section{References}

(1) Fryer, P. J.; Robbins, P. T.; Cole, P. M.; Goode, K. R.; Zhang, Z.; Asteriadou, K. Populating the cleaning map: can data for cleaning be relevant across different lengthscales? Procedia Food Sci. 2011, 1, 1761-1767.

(2) Akhtar, N.; Bowen, J.; Asteriadou, K.; Zhang, Z.; Fryer, P. J. Matching the nano- to the meso-scale: measuring deposit-surface interactions with atomic force microscopy and micromanipulation. Food Bioprod. Process. 2010, 88, 341-348. 
(3) Bani Kananeh, A.; Scharnbeck, E.; Kück, U. D.; Räbiger, N. Reduction of milk fouling inside gasketed plate heat exchanger using nano-coatings. Food Bioprod. Process. 2010, 88, $349-356$.

(4) Asteriadou, K.; Othman, A. M.; Goode, K.; Fryer, P. J. Improving cleaning of industrial heat inducted food and beverages deposits: a scientific approach to practice. In Proceedings of International Conference on Heat Exchanger Fouling and Cleaning VIII; MüllerSteinhagen, H., Malayeri, M. R., Watkinson, A. P., Eds.; June 14-19, 2009, Schladming, Austria; pp 158-164.

(5) Goode, K. R.; Asteriadou, K.; Robbins, P. T.; Fryer, P. J. Fouling and cleaning studies in the food and beverage industry classified by cleaning type. Compr. Rev. Food Sci. Food Saf. 2013, 12, 121-143.

(6) Palabayik, I.; Yilmaz, M. T.; Fryer, P. J.; Robbins, P. T.; Toker, O. S. Minimising the environmental footprint of industrial scaled cleaning processes by optimisation of a novel clean-in-place system protocol. J. Clean. Prod. 2015, 108, 1009-1018.

(7) Liu, W.; Fryer, P. J.; Zhang, Z.; Zhao, Q.; Liu, Y. Identification of cohesive and adhesive effects in the cleaning of food fouling deposits. Innov. food sci. \& emerg. technol. 2006, 7, 263-269.

(8) Gillham, C. R.; Fryer, P. J.; Hasting, A. P. M.; Wilson, D. I. Enhanced cleaning of whey protein deposits using pulsed flows. J. Food Eng. 2000, 46, 199-209.

(9) Fan, M.; Phinney, D. M.; Heldman, D. R. Effectiveness of rinse water during in-place cleaning of stainless steel pipe lines. J. Food Sci. 2015, 80, 1490-1497. 
(10) Jude, B.; Lemaire, E. How to optimize clean-in-place (CIP) processes in food and beverage operations. Schneider Electric. 2013. http://www2.schneiderelectric.com/documents/support/white-papers/energy-efficiency/how-to-optimize-clear-inplace-CIP-processes.pdf (accessed April 2017).

(11) Martin, E.; Montague, G.; Robbins, P. A quality by design approach to process plant cleaning. Chem. Eng. Res. Des. 2013, 91, 1095-1105.

(12) Christian, G. K.; Fryer, P. J. The effect of pulsing cleaning chemicals on the cleaning of whey protein deposits. Food Bioprod. Process. 2006, 84, 320-328.

(13) Van Asselt, A. J.; Van Houwelingen, G.; Te Giffel, M. C. Monitoring system for improving cleaning efficiency of cleaning-in-place processes in dairy environments. Food Bioprod. Process. 2002, 80, 276-280.

(14) Khalid, N. I.; Aziz, N. A.; Nuraini, A. A.; Taip, F. S.; Anuar, M. S. Alkaline cleaningin-place of pink guava puree fouling deposit using lab-scale cleaning test rig. Agric. Agric. Sci. Procedia 2014, 2, 280-288.

(15) Fuchs, E.; Boye, A.; Murcerk, R.; Majschak, J.-P. An experimental comparison of film flow parameters and cleaning behaviour of falling fluid films for different tilt angles. Food Bioprod. Process. 2015, 93, 318-326.

(16) Úbeda, M. A.; Hussein, W. B.; Hussein, M. A.; Hinrichs, J.; Becker, T. M. Acoustic sensing and signal processing techniques for monitoring milk fouling cleaning operations. Eng. Life Sci. 2016, 16, 67-77. 
(17) Liu, W.; Christian, G. K.; Zhang, Z.; Fryer, P. J. Direct measurement of the force required to disrupt and remove fouling deposits of whey protein concentrate. Int. Dairy J. 2006, 16, 164-172.

(18) Piepiórka-Stepul, J.; Diakun, J.; Mierzejewska, S. Poly-optimization of cleaning conditions for pipe systems and plate heat exchangers contaminated with hot milk using the cleaning in place method. J. Cleaner Prod. 2016, 112, 946-952.

(19) Mintel. Allergies and Allergy Remedies - UK. Online report. 2010. $\underline{\text { http://store.mintel.com/allergies-and-allergy-remedies-uk-february-2010 (accessed April }}$ 2017). Food Standards $\quad$ Agency. $\quad 14 \quad$ Allergens. 2014. https://www.food.gov.uk/sites/default/files/top-allergy-types.pdf (accessed May 2016).

(21) Fryer, P. J.; Robbins, P. T.; Asteriadou, K. Current knowledge in hygienic design: can we minimize fouling and speed cleaning? Procedia Food Sci. 2011, 1, 1753-1760.

(22) Goode, K. R.; Asteriadou, K.; Fryer, P. J.; Picksley, M.; Robbins, P. T. Characterising the cleaning mechanisms of yeast and the implications for cleaning in place (CIP). Food Bioprod. Process. 2010, 88, 365-374.

(23) Cole, P. A.; Asteriadou, K.; Robbins, P. T.; Owen, E. G.; Montague, G. A.; Fryer, P. J. Comparison of cleaning of toothpaste from surfaces and pilot scale pipework. Food Bioprod. Process. 2010, 88, 392-400. 


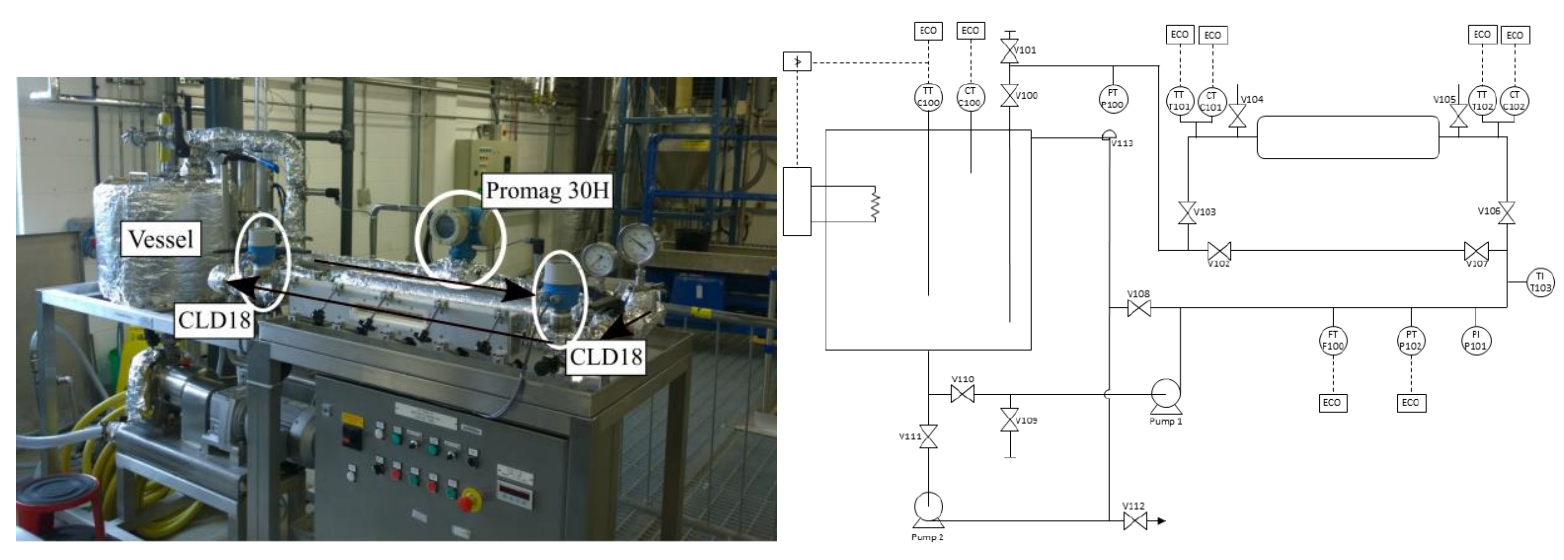

Figure 1. Pilot scale cleaning rig used for the experiments. (a) The key parts are labeled and the arrows illustrate the direction of fluid flow and (b) P\&ID for the rig.

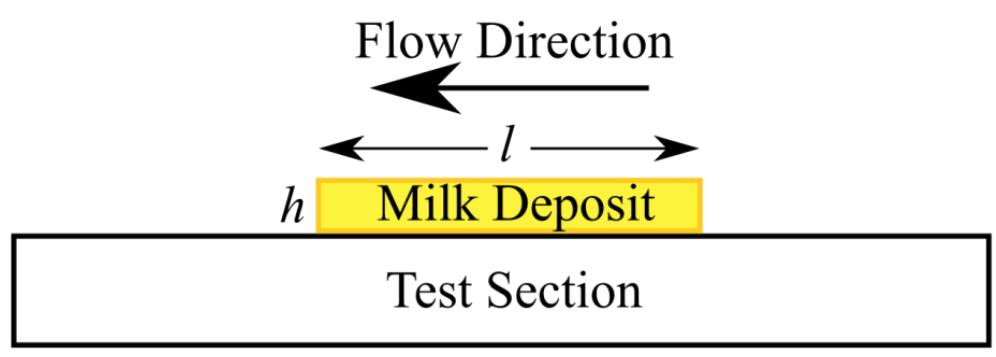

Figure 2. Diagram of the side view of milk paste on test section, with key parameters labeled. 


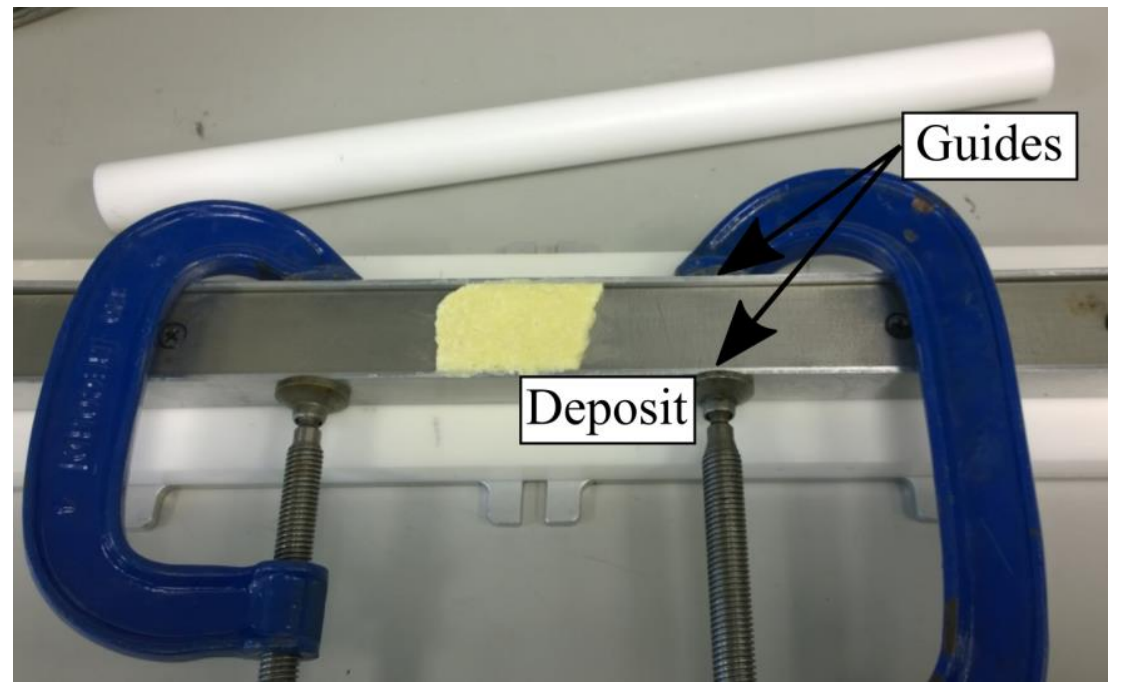

Figure 3. Preparation of the milk paste, showing the guides for creating the fixed thickness.

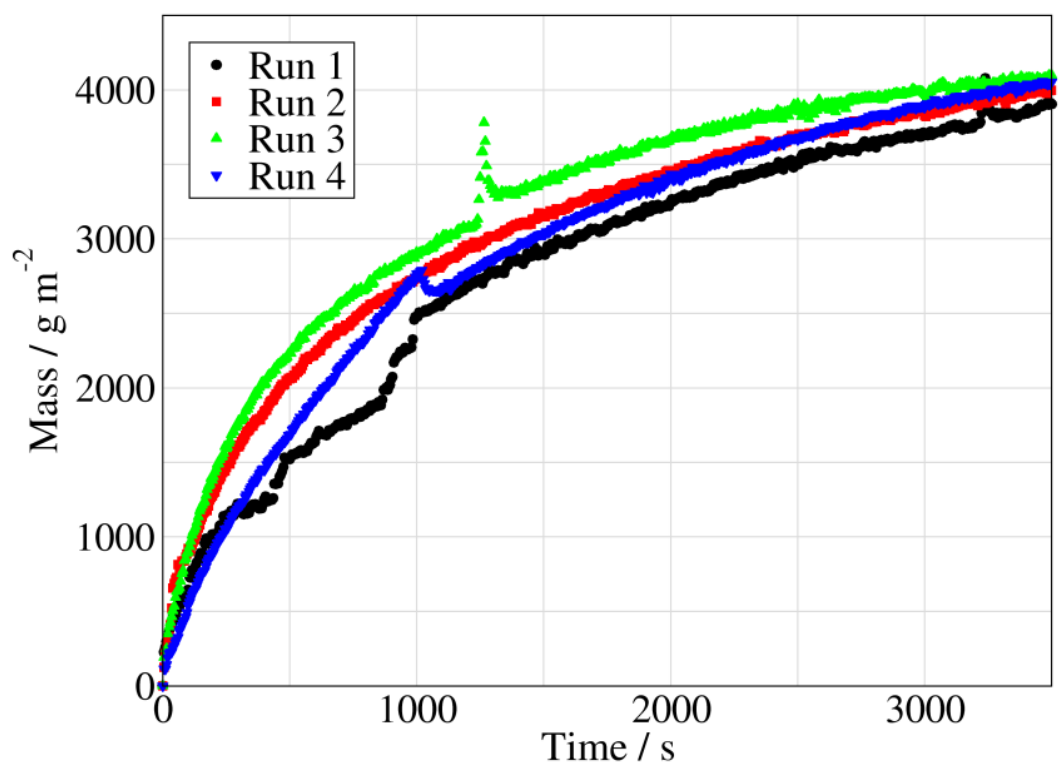

Figure 4. Repeatability of runs at a velocity of $1.02 \mathrm{~ms}^{-1}$ at $40^{\circ} \mathrm{C}$ for the measure of the mass of milk paste removed from the surface. 


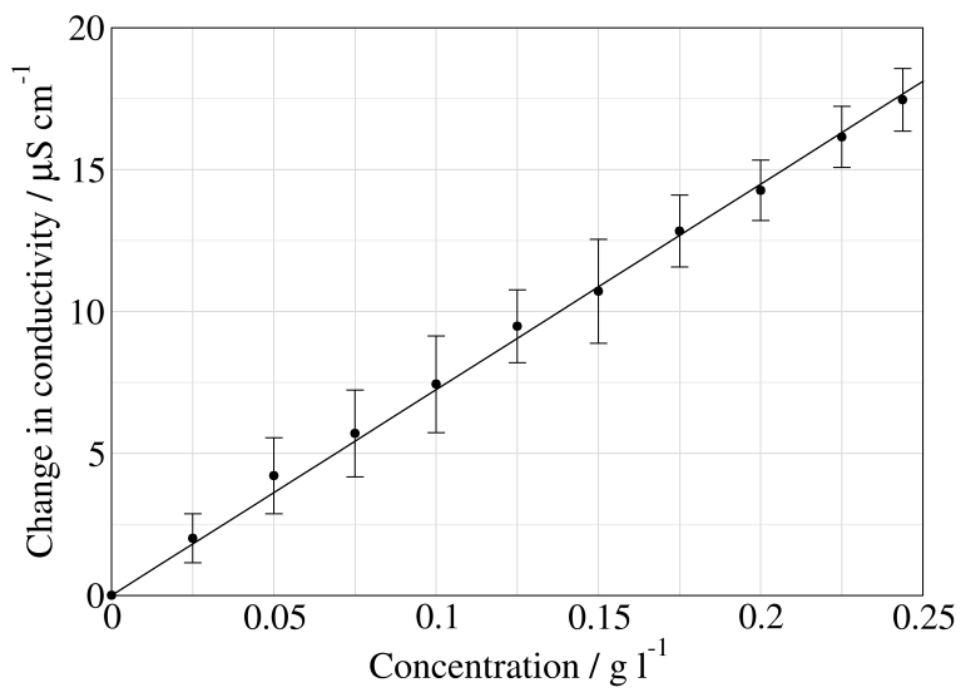

Figure 5. Calibration curve for the measured conductivity change with the concentration of the milk in water for temperatures from 40 to $80^{\circ} \mathrm{C}$. The error bars show the range.

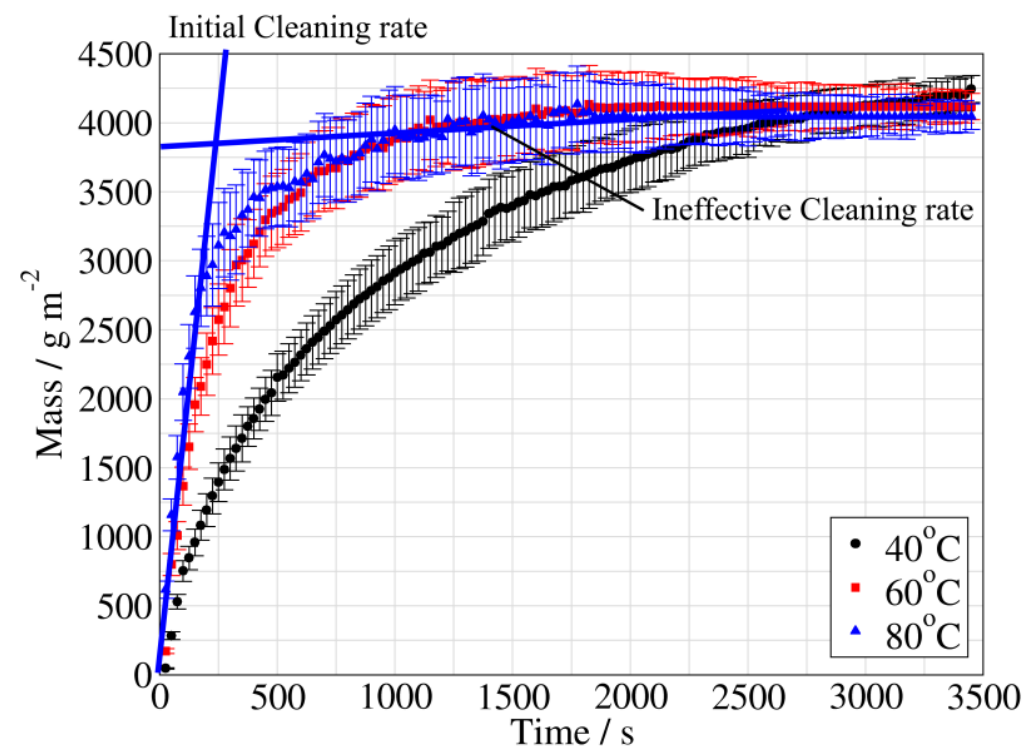

Figure 6. Quantity of milk paste removed from the test section at varying temperatures using water at $1.48 \mathrm{~ms}^{-1}$. The error bars show 2 standard deviations from the average results. This 
initial cleaning rate and the ineffective cleaning rate are shown for the $80{ }^{\circ} \mathrm{C}$ cleaning process.

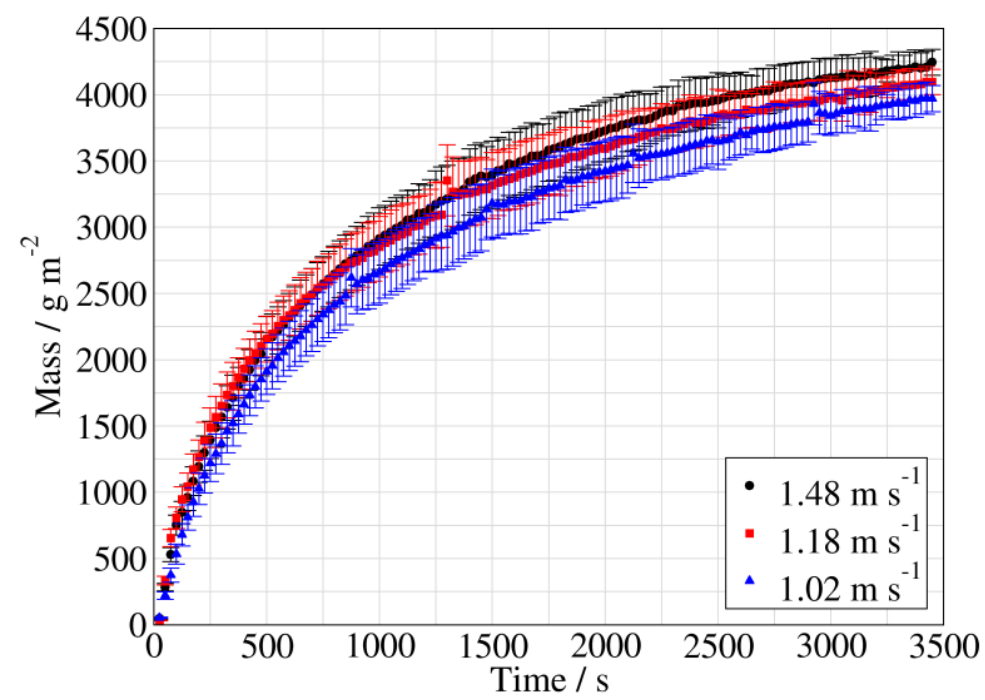

Figure 7. Quantity of milk paste removed from the test section at varying velocities using water at $40^{\circ} \mathrm{C}$. The error bars show 2 standard deviations from the average results.

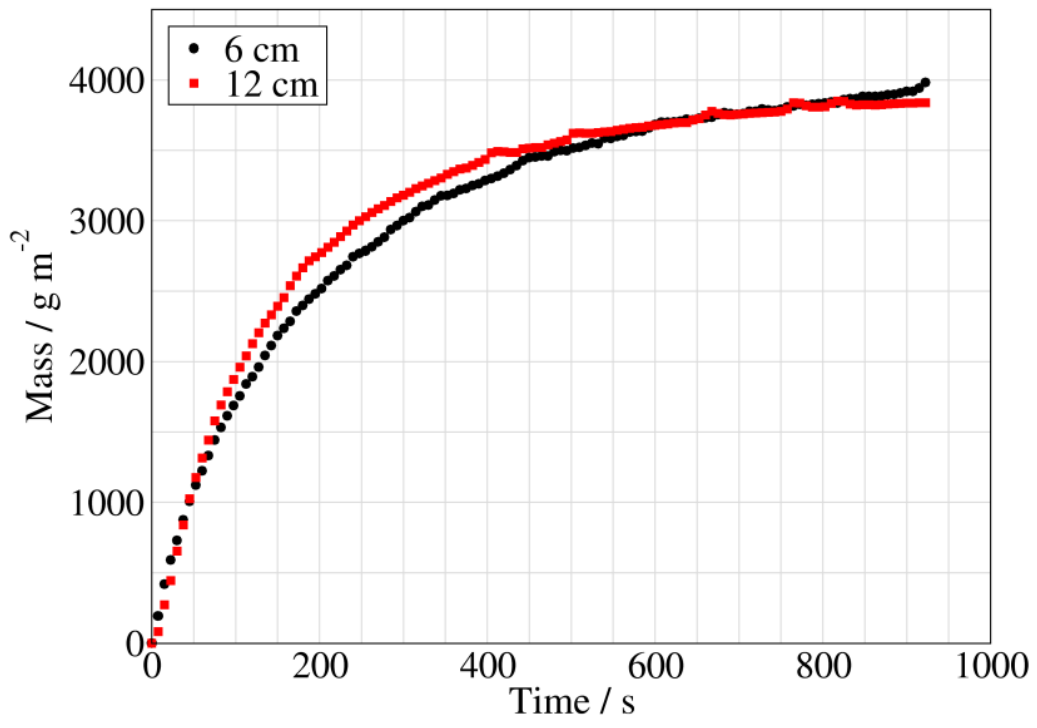


Figure 8. Quantity of milk paste removed from the test section at $60^{\circ} \mathrm{C}$ and $1.48 \mathrm{~ms}^{-1}$ using water for pastes of different lengths.
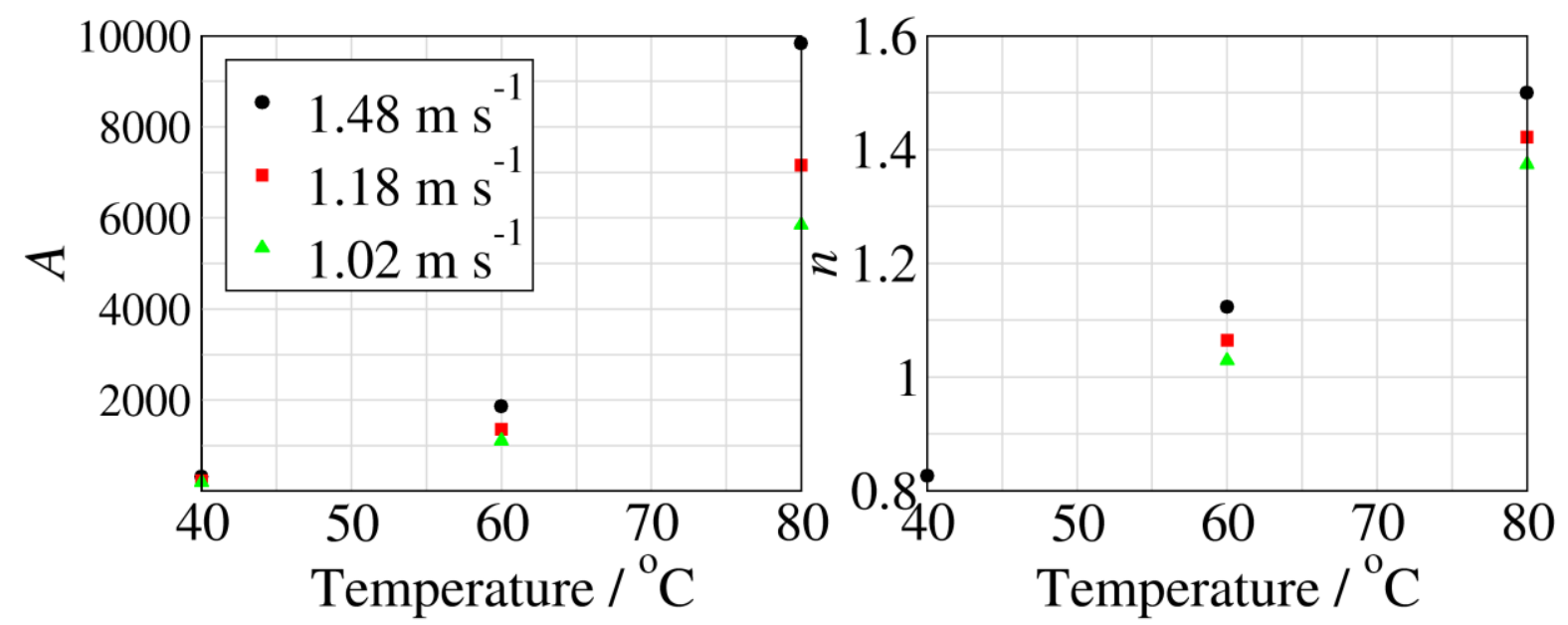

Figure 9. Variation of the parameters $A$ and $n$ with the temperature and the velocity for water.

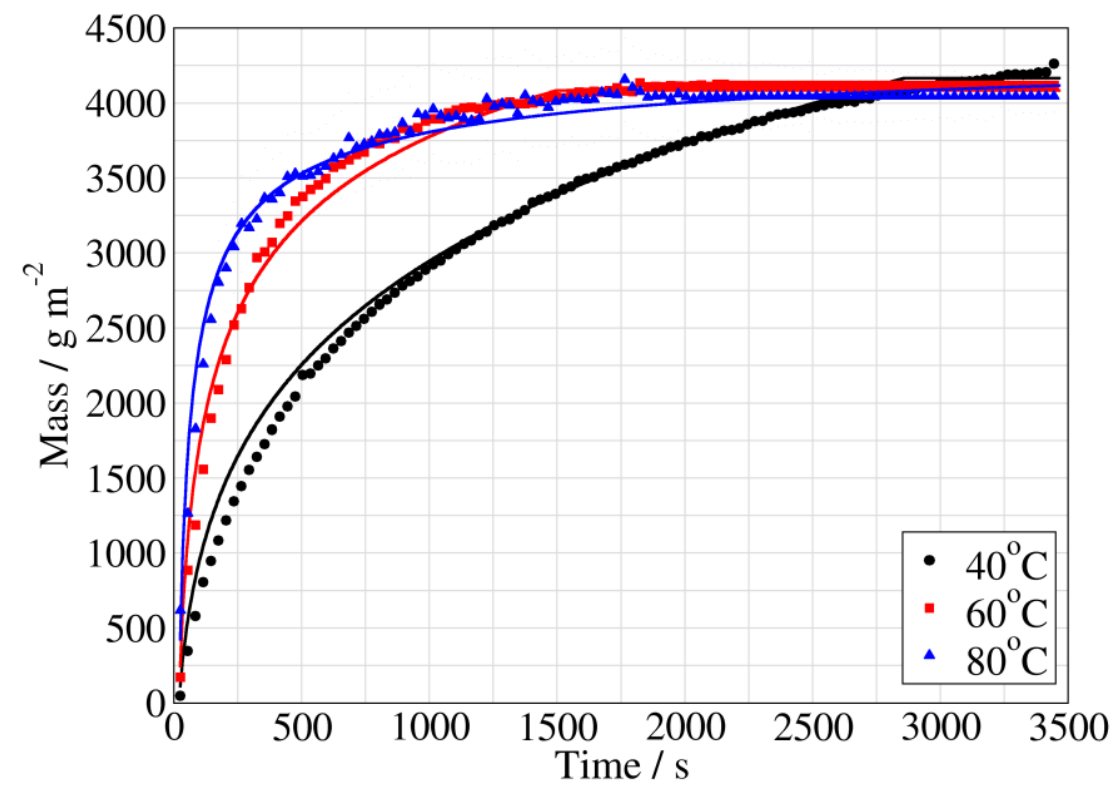

Figure 10. Quantity of milk paste removed from the test section at varying temperatures using water at $1.48 \mathrm{~ms}^{-1}$ with the predicted values shown as the lines. The error bars show 2 standard deviations from the average results. 


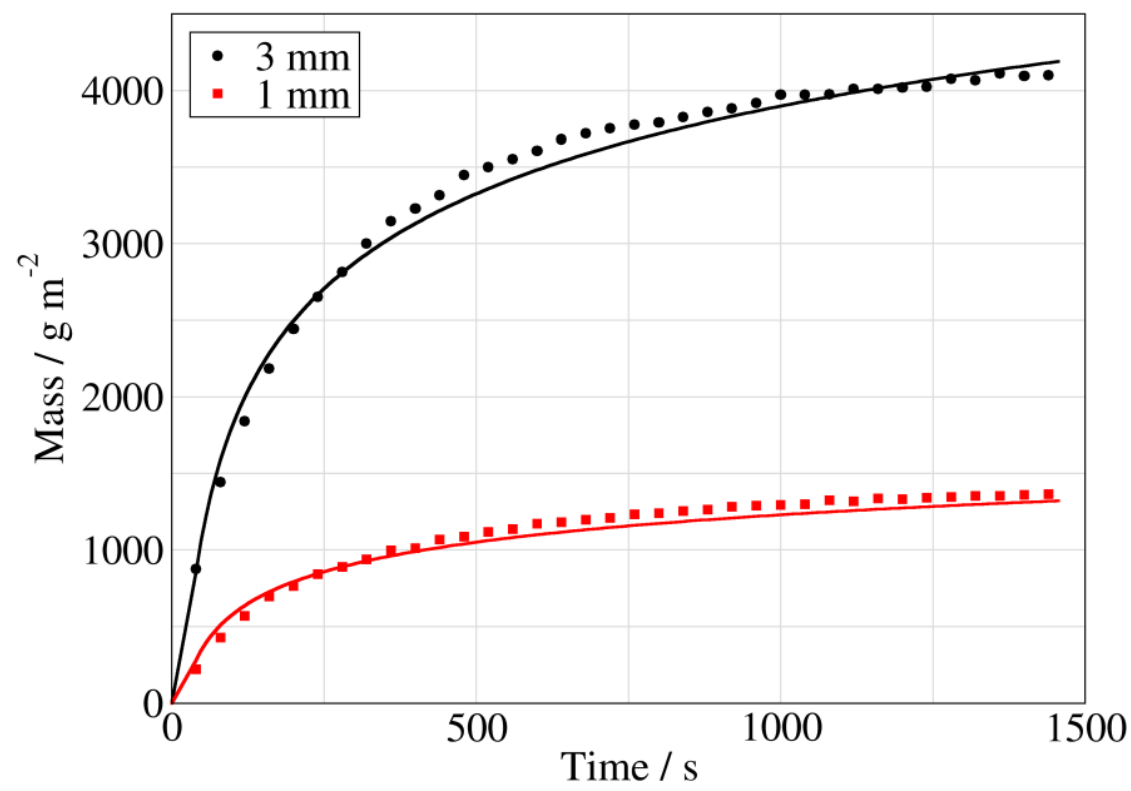

Figure 11. Quantity of milk paste removed from the test section at $60^{\circ} \mathrm{C}$ and $1.48 \mathrm{~ms}^{-1}$ using water for pastes of different heights. The lines show the predicted values for the two heights.

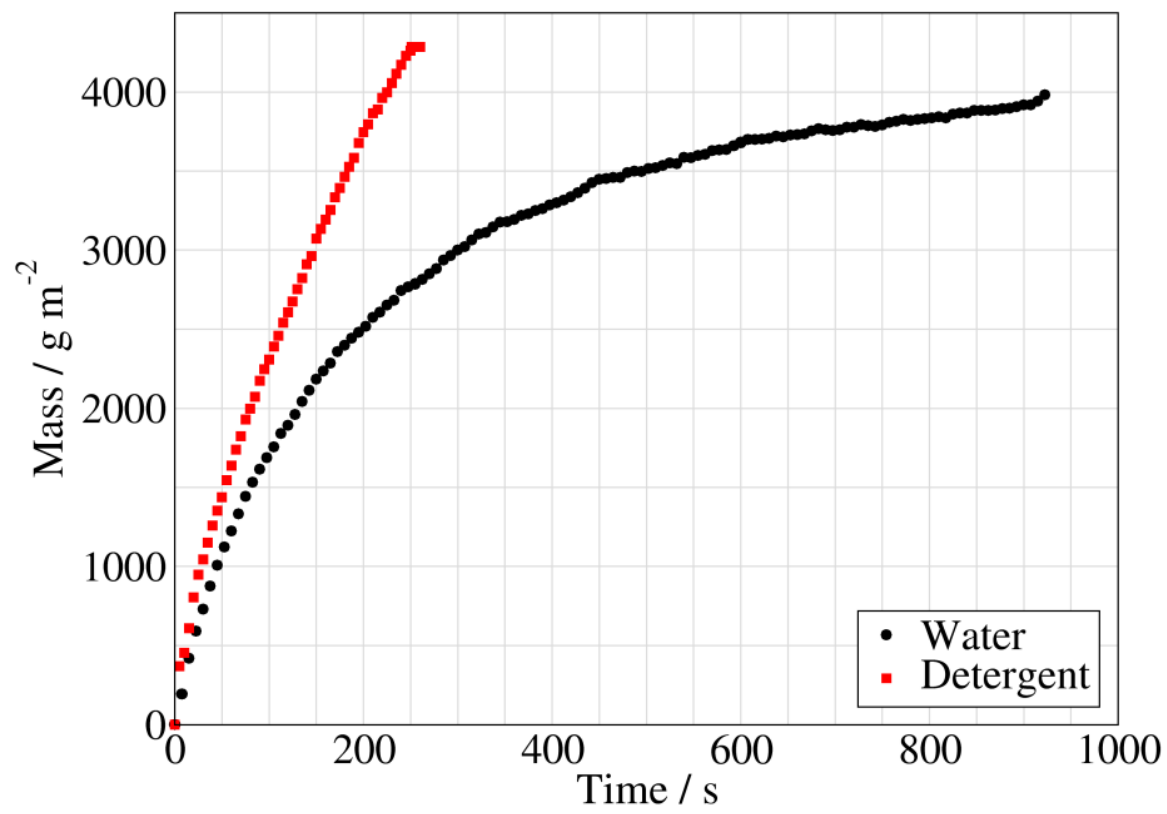


Figure 12. Quantity of milk paste removed from the test section at $60^{\circ} \mathrm{C}$ and $1.48 \mathrm{~ms}^{-1}$ using water and detergent.
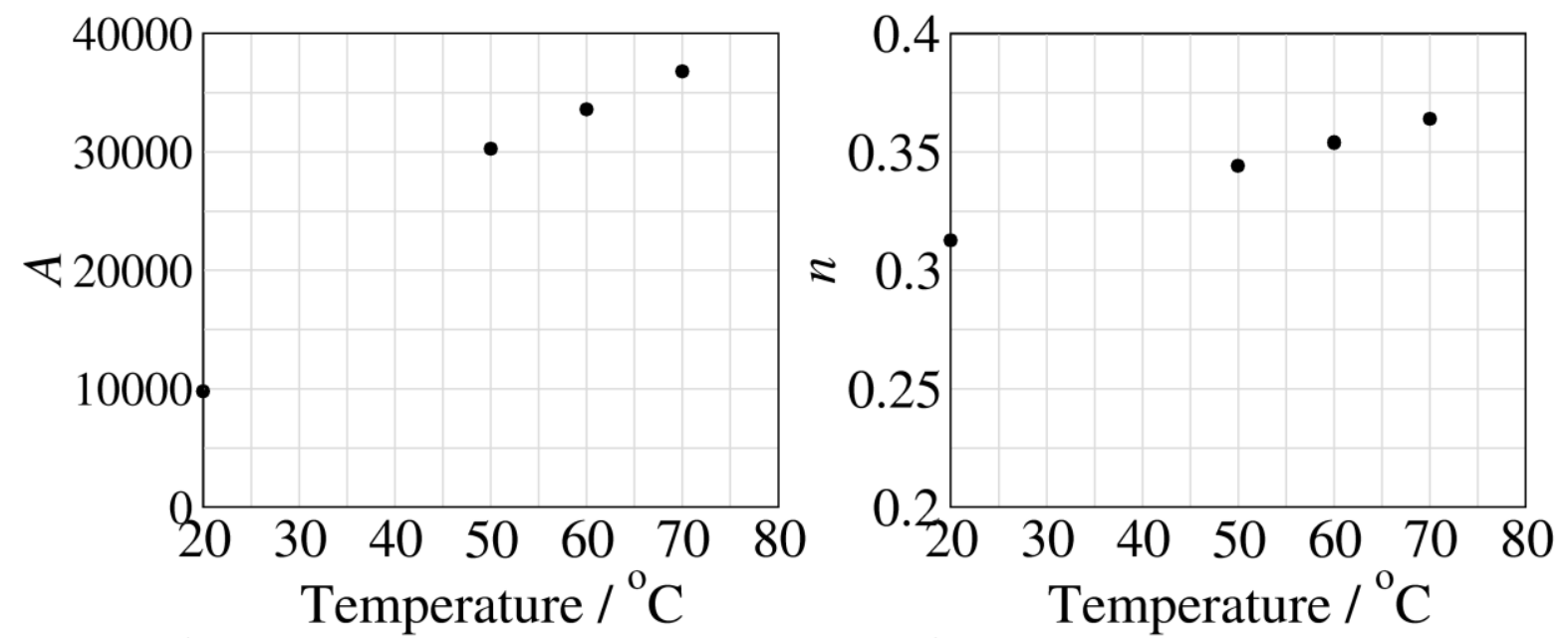

Figure 13. Variation of the parameters $A$ and $n$ with the temperature at a velocity of $1.48 \mathrm{~ms}^{-1}$ for the detergent.

\begin{tabular}{|c|c|c|c|}
\hline Product Name & Production Function & Quantity in Rig & Manufacturer \\
\hline Ecograph T RSG35 & Data Manager & 1 & Endress \& Hauser, \\
& & $(\mathrm{ECO})$ & Manchester, UK \\
\hline Smartec CLD 18 & Conductivity and & 2 & Endress \& Hauser, \\
& Temperature Sensor & $(\mathrm{C} 101, \mathrm{C} 102)$ & Manchester, UK \\
\hline Promag 30H & Flow Rate Sensor & 1 & Endress \& Hauser, \\
& & $(\mathrm{F} 100)$ & Manchester, UK \\
\hline Condumax CLS15 & Conductivity Sensor & 1 & Endress \& Hauser, \\
& & $(\mathrm{C} 100)$ & Manchester, UK \\
\hline
\end{tabular}




\begin{tabular}{|c|c|c|c|}
\hline Eurotherm 2416 & Temperature & 1 & Eurotherm, Worthing, \\
& Controller & UK \\
\hline Cerebar T PMP 135 & Pressure Sensor & 2 & Endress \& Hauser, \\
& & $(\mathrm{P} 100, \mathrm{P} 101)$ & Manchester, UK \\
\hline
\end{tabular}

Table 1. List of instrumentation available on the cleaning rig, labels correspond to Figure 1 (b).

For Table of Contents Only

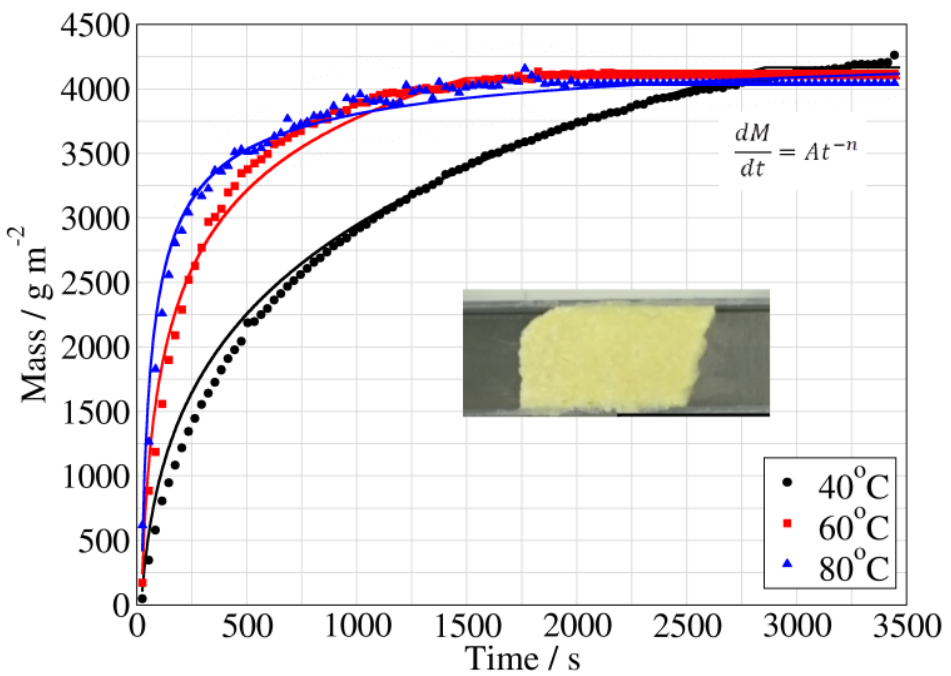


2017-05-18

\title{
A rate-based approach to cleaning-in-place
}

\author{
Trinh, Linda
}

American Chemical Society

Linda Trinh, A. Roy Willey, Peter J. Martin, Jon Ashley, Ibtisam E. Tothill and Thomas Lawrence

Rodgers. A rate-based approach to cleaning-in-place. Industrial and Engineering Chemistry

Research, Vol. 56, Issue. 23, 14 June 2017, pp.6695-6702

10.1021/acs.iecr.7b00727

Downloaded from Cranfield Library Services E-Repository 